\title{
0 retorno da aula expositiva no ensino de História: notas para uma prática fabulatória
}

\author{
Nilton Mullet Pereira* \\ Gabriel Torelly*
}

\section{Resumo}

O texto trata do elemento central do fazer docente e do ensino de História: a aula expositiva. Argumenta a respeito do papel da aula expositiva e problematiza o caráter narrativo da exposição do professor de História, uma vez que este cria um cenário e dá um tom dramático à narrativa histórica. Problematiza a exposição didática e oferece uma análise das críticas que essa estratégia tem recebido. Nesse sentido, procura-se despir a aula expositiva do tom seco e árido que sempre a acompanhou, bem como da sua íntima ligação com um ensino tradicional de História. Do mesmo modo, pretende-se dar relevância aos diferentes modos expressivos que acompanham a narrativa didática na aula, afirmando-se que esse é um dos momentos mais importantes e decisivos da relação ensino-aprendizagem nesse conteúdo. Além disso, a teorização a respeito da faculdade da fabulação pode bem permitir uma nova experiência com aulas expositivas, uma vez sustentada a ideia de que uma exposição oral em uma aula de História implica uma estratégia fabulatória.

Palavras-chave: Aula expositiva. Fabulação. Ensino.

Nos tempos atuais, muito se critica a exposição oral em sala de aula, a famosa aula expositiva. As críticas dizem respeito, por um lado, ao tom cansativo e pedante da exposição e, por outro, referem-se ao seu caráter tradicional, que não supõe a participação do aluno em sua própria aprendizagem. Ainda que os dois argumentos não possam ser aceitos como obstáculos à aula expositiva ou à exposição oral do professor de História, a defesa, a qual desejamos fazer neste artigo, da aula expositiva em História, tanto para o ensino fundamental, quanto para o ensino médio, irá valer-se desses dois elementos de crítica.

Recebido: 10/04/2014 - Aprovado: 03/06/2014

http://dx.doi.org/10.5335/rep.v21i2.4302

Graduado em História e Doutor em Educação. Professor da área de ensino de História na Universidade Federal do Rio Grande do Sul. E-mail: niltonmp.pead@gmail.com.

** Graduado em História e Mestre em Educação pela Universidade Federal do Rio Grande do Sul. Professor de História do Projeto Educacional Alternativa Cidadã. E-mail: gabrieltorelly@gmail.com. 


\section{A exposição do problema e a espiral do discurso redundante}

Uma exposição oral certamente encontra muitos obstáculos e limites nestes tempos, nos quais os estudantes parecem ter pouca paciência para a disciplina acadêmica e para a parte mais prosaica da aula de História, aquela que, por fora do jogo, do lúdico, das imagens, dos fragmentos de filmes ou das histórias em quadrinhos, preocupa-se em organizar os argumentos e expô-los aos estudantes na forma de um discurso argumentativo. Entretanto, é importante compreender que a sala de aula de História é um espaço que pode conviver com o plano da ludicidade ${ }^{1}$, mas a prosa é parte indispensável da formação das novas gerações, em uma sociedade letrada como a nossa. Nesse sentido, parece necessário pensar que a exposição oral pode ser, sob certo aspecto, um modo de promover a disciplina acadêmica para uma geração acostumada com as redes sociais, com o computador e com os games. Disciplina acadêmica não é outra coisa senão a competência de desenvolver hábitos de estudo, que implica o envolvimento com a leitura de livros, a escrita de textos e a abertura para aprender por meio da exposição argumentativa. Trata-se de aprender com outro tempo: o tempo da pesquisa, o tempo do estudo, que se difere do tempo da brincadeira, do vídeo game ou das redes sociais. O que nos resta, portanto, é redefinir, no âmbito da sala de aula de História esse tempo da pesquisa, quem sabe inserindo-nos, primeiro, no tempo do jogo, no tempo da fabulação.

A aula expositiva esteve ligada, via de regra, a um processo de transmissão de informações históricas para os estudantes. Então, é comum supor que ministrar uma aula expositiva tem a ver com informar/comunicar e representar, duas funções comuns a uma linguagem representacional, ${ }^{2}$ que informa algo e que representa uma realidade passada, de maneira que o ensino da História por meio da exposição oral torne-se um processo de cristalização do que é o passado, dando a sensação aos estudantes e ao próprio professor de que a História é, em si mesma, um passado facilmente representado e informado pela via da fala do docente.

É assim que a aula expositiva tornou-se objeto da crítica de diversas tendências pedagógicas e é do mesmo modo que essa transformou-se no principal artifício da aula de História - na sua forma representacional e informativa - como um relato, geralmente, descritivo e preocupado substancialmente com duas questões centrais da docência em História, em primeiro lugar, a obsessão pela informação, o que supõe ser a função do ensino de História unicamente a transmissão de erudição histórica e de um acúmulo de informações. Dessa maneira, o melhor modo de informar seria por meio da linguagem falada. Isso tem passado de geração em geração e parece ser um limite bastante difícil de transpor no campo do ensino dessa disciplina. O papel da erudição e da informação assume a centralidade na sala de 
aula, de modo que, se não há a aula expositiva, não há acúmulo e nem formação de pensamento histórico. Tudo se passa como se essa obsessão pela informação fosse o que sempre se considerou como a batalha por vencer o conteúdo, na suposição de que uma boa aula de História resultaria do reconhecimento de uma grande quantidade de conteúdos. Em segundo lugar, a obsessão pela representação, que decorre da suposição de que ensinar História é definir as fronteiras do passado, de modo que o aluno consiga dar sentido de tudo o que escuta. A exposição é, em geral, um monólogo que recria o passado na forma de um conjunto de representações que se confundem com o próprio passado, dando a este um tom de definitivo, irrecorrível e copiado. $\mathrm{O}$ interessante é que isso ocorre como resultado de uma aula expositiva que descreve e informa, ainda que quem ministre tal aula não acredite, teoricamente, que seja possível copiar ou recriar o passado em limites pré-determinados. O que importa é que a estratégia expositiva, na medida em que apenas informa e representa, deixa os estudantes sem a opção pelo "se" ou pelo "e se tivesse ocorrido de outra maneira?", ou seja, não se coloca uma nuvem envolto aos acontecimentos, dando a estes possibilidades se serem diferentes.

Cainelli realizou pesquisa junto aos estagiários de História e verificou que a aula expositiva justiçava-se pelo fato de que os alunos precisam dos conteúdos que ainda não sabem. Argumenta a autora que

[...] a aula expositiva funcionaria como uma possibilidade para o estagiário ensinar sua versão dos fatos históricos para os alunos ou, dito de outra forma, ensinar o que seria necessário sobre o conteúdo. Nos relatórios, os estagiários argumentam que sem a aula expositiva é impossível discutir conteúdos ou trabalhar outros exercícios, pois a iniciação ao conteúdo depende da exposição do professor. Este pensamento reflete, em última instância, a ideia de que os conhecimentos dos alunos sobre a história precisariam da legitimação do conhecimento científico representado, neste caso, pela figura do estagiário (CAINELLI, 2009, p. 178).

A crítica acerca do caráter cansativo e pedante da aula expositiva precisa ser levada em consideração. Inegavelmente, os estudantes da escola básica em geral, e especificamente do ensino fundamental, não estão previamente dispostos a assumir o papel de espectadores de alguém que recita um discurso que se repete, se alonga no tempo e se aparta da vida. Pensadores como Jean Piaget (1896-1980) e Lev Vygotsky (1896-1934), por exemplo, deram contornos muito diversos à atividade professoral, que se resumia, em tempos passados, a uma exposição presunçosa dos conteúdos. A partir da entrada, particularmente no Brasil, da contribuição desses pensadores, a aula em geral e, em particular, a aula de História, passou a ser vista como um espaço no qual a diversidade das propostas pedagógicas deveriam considerar a ação do estudante, fator que diminuiu drasticamente o papel da aula expositiva. Em verdade, esta passou a ser vista como a grande vilã, pois colocava o 
estudante na situação de uma tábula rasa, passiva e não participante do processo do conhecimento. Em nossa concepção, entretanto, a exposição didática é, antes de tudo, a exposição de um problema.

Pensamos que consiste, sobretudo, na exposição de um problema investigativo, que se vale da elaboração de um argumento disparador e de uma ou de várias perguntas, a partir do que se procura, com demonstração empírica e argumentos auxiliares, afirmar uma verdade histórica. Além disso, a exposição precisa ser circular, ou seja, retornar redundantemente ao argumento disparador de maneira a fazer com que as fabulações, as comparações, os exemplos, não afastem o estudante da problemática proposta no início.

Nesse sentido, a exposição procura recriar o argumento da pesquisa que levou o investigador a determinadas conclusões, mas o faz utilizando-se de uma narrativa diversa daquela utilizada pelo historiador, uma vez que o público que irá ouvir e dialogar com a aula expositiva não é "iniciado" nos conceitos da disciplina, ao contrário, é um aprendiz desses conceitos. Além disso, é preciso considerar que o uso que os estudantes farão desses conceitos não é o mesmo que os historiadores e professores de História fazem. Os estudantes aprendem conceitos históricos para compreender o seu mundo e os mundos alheios (PEREIRA; SEFFNER, 2009). Aprendem a respeito do seu mundo para intervir nesse, mas aprendem com as experiências de outros mundos para poder criar novos mundos possíveis. Assim, o uso dos conceitos históricos não é outro senão para expandir a vida, as possibilidades de vida (PEREIRA, 2013). Logo, conclui-se que a exposição didática precisa levar em consideração tal especificidade e que, desse modo, precisa usar de muitas estratégias narrativas para expressar, na forma do discurso oral, os argumentos da pesquisa e os conceitos históricos.

Nesse sentido, valorizar a exposição didática é chamar a atenção para a criação de relações necessárias entre as práticas escolares e a pesquisa histórica, de modo que a esta possa ser instrumento de compreensão das práticas sociais historicamente datadas e que as práticas escolares possam chamar os professores, compreendendo a cultura escolar, a colocar à disposição das novas gerações os debates do âmbito historiográfico e os resultados da pesquisa histórica.

Desse modo, uma exposição didática é um pequeno movimento de problematização da realidade histórica. Um movimento que se dá por meio de uma série de elementos constitutivos, mas que inicia sempre por perguntas provocativas.

$\mathrm{E}$ isso tem muitas consequências. Ao expor um problema, o professor abandona o velho hábito de uma narrativa linear da História, que apresenta fatos, causas e consequências. Ao expor o problema, o professor constitui um discurso redundante, que, em uma espécie de espiral, volta ao problema o tempo todo, mas com novas 
argumentações, novas relações e novos exemplos. Ora, a exposição de um problema afasta-se da narrativa pedante e cansativa, uma vez que se insere na própria duração dos estudantes, procura flagrar seu tempo, seus movimentos e provoca encontros. Encontros com a História, mas também com certo estilo docente, que consiste na arte de arranjar os argumentos, dando a estes tonalidades vocais, elementos gestuais, $\mathrm{e}$ um conjunto de insistentes provocações, na forma de perguntas e questionamentos.

\section{0 jogo fabulatório e os elementos narrativos}

É assim que a exposição torna-se um jogo. Um jogo no qual não apenas o professor protagoniza, mas também o aluno, uma vez que a sua duração coincide com a duração do professor. Nesse sentido, temos o segundo elemento de crítica, ou seja, a noção de que na aula expositiva temos uma passividade do aluno. Ao contrário, a aula expositiva é um convite ao movimento. Pois a coincidência entre o que dura no aluno e o que dura no professor permite pensar a exposição como um jogo fabulatório que, de posse da mais rigorosa verdade histórica, é capaz de permitir a imaginação. Eis o elemento central. $\mathrm{O}$ aluno pode até mesmo não falar, apenas escutar, mas sua escuta pode implicar em um processo de reconstrução, no seu espírito, daqueles ditos que saem da boca do professor. Uma espécie de nova criação - na forma da imaginação (uma vez que há uma ligação, uma interpenetração das diversas imagens recebidas do discurso professoral), de toda uma história contada.

Pois é essa viagem imaginativa que a aula expositiva precisa provocar no estudante. De modo que este não seja um papel em branco ou um receptáculo que absorve sem crítica ou sem intervenção de tudo o que é dito. Ou ainda, por outra parte, o aluno, ao não ter encontros com o discurso do professor e ao não se deixar agenciar pela situação da aula, não imagina, não cria novamente, de modo que se pode dizer que o discurso "entra por um ouvido e sai pelo outro".

Eis, finalmente, a sina de boa parte das exposições orais: o discurso "entra por um ouvido e sai pelo outro". Como ultrapassar esse limite? É o que propomos ao supor que a aula expositiva seja a provocação de uma agência - do professor e do aluno, ao supor que a aula expositiva consiste em contar histórias que se vale do seguinte:

a) do uso de recursos narrativos que insiram o estudante no universo da História contada, para o que se pode valer de gestos, de analogias, da entonação de voz, de exemplos cotidianos, de metáforas, de fabulação, em um processo de multiplicação dos acontecimentos. Essas perspectivas, supondo a necessidade de um rigor conceitual, considerando, portanto, que tais recursos narrativos, não esvaziam o sentido forte de cada conceito, mas ajudam na sua profunda compreensão; 
b) do abuso de narrativas curtas, ou seja, de pensar que o tempo do aluno, não é o tempo da pesquisa ou do próprio professor. Assim, o respeito às possibilidades do estudante em dar atenção é elemento fundamental para o sucesso da aula;

c) de pensar a narrativa como contar uma história, mas uma história que se faz sempre a partir de um problema, o qual mobiliza, que enseja perguntas que dão conta tanto de um total estranhamento por parte dos alunos, quanto de uma significativa aproximação com o que o aluno gosta e vive. Uma pergunta bem formulada provoca e chama a atenção do estudante para 0 que está sendo contado;

d) de multiplicar os acontecimentos. Um professor de História transita por áreas diversas e é dono de uma boa erudição, logo sua exposição pode muito bem falar da Era Vargas e circular pelos exemplos da música, do cinema, da literatura e até da televisão. Isso permite ao aluno estabelecer conexões e dar sentido ao que escuta. Então, multiplicar os acontecimentos é uma espécie de brincadeira séria com o conteúdo da História, com a criação de relações, comparações e distinções entre épocas, governos, culturas, etc.

Desse modo, parece importante considerar que aula expositiva é um instrumento decisivo na vida do professor de História, enfatizando seu caráter de pura provocação da imaginação dos estudantes.

\section{A palavra, a sala de aula e a fabulação}

Não se trata de reinventar a roda e, pior para nós, nesse caso, seria ainda uma roda muito velha e antiga. Trata-se de dar uma resposta a uma conjuntura específica que, se não reflete apenas a educação e a formação, tem aí, inegavelmente, uma incidência profunda. Nos mais variados meios, sustenta-se que o poder das palavras está esgotado: ou bem as palavras foram completamente penetradas pelo dinheiro e pelo "espírito do comércio", o que reduziria o seu poder de encantamento e sua capacidade poética de expressar diversidade de sentires e de pensares; ou bem as palavras já não são os veículos mais adequados para o entendimento, uma vez que teriam sido superadas pela dinâmica utilitária da multifacetada aparelhagem tecnológica.

De certo modo, é preciso reconhecer que a palavra tem uma função lógica, ou uma dimensão estritamente utilitária. Bem articulada aos símbolos, essa é o veículo orientador da percepção convencional, permitindo à inteligência encontrar a cada dia no mundo os encaixes e as relações mais adequadas entre as palavras e 
as coisas. Nesse sentido, a palavra tem função de designar, de tornar claro os contornos de determinada situação, incidente ou acontecimento. Ela carrega o poder de organizar e de comunicar uma ação, a partir de fios comunicantes intersubjetivos que são compreendidos por uma rede de indivíduos atentos e dispostos em um determinado grau de atenção. Neste caso, a palavra percorre um intervalo mínimo até encontrar uma representação intelectual das coisas, articulando-se rapidamente com o conjunto subjetivo de lembranças pessoais que todos carregamos para produzir uma imagem do mundo. Essa imagem, produzida pela sensação de uma palavra capturada entre as lembranças individuais e a percepção atenta, é a forma que damos àquilo que aprendemos, seja em um passeio no parque, em uma pescaria de domingo, ou em uma aula de História.

No entanto, quando contamos uma história, expomos um problema, fazemos desfilar determinados personagens ante os olhos, os ouvidos e todos os sentidos dos alunos, não é apenas a função lógica da palavra que teremos como interlocutor na produção do conhecimento. Antes de formarmos uma representação intelectual da história contada, é a imaginação que é posta para funcionar. E se não quisermos entender por imaginação apenas uma forma diminuída da inteligência, ou uma imagem incompleta e confusa da realidade, melhor seria chamá-la de "fabulação"3. A fabulação é a forma assumida pela imaginação quando tomamos em conta sua dimensão produtiva e criadora, seu caráter irredutível e incomensurável em relação a qualquer modelo de significação. Trata-se, portanto, de uma faculdade singular presente nos seres humanos, notavelmente desenvolvida em romancistas, poetas, dramaturgos e professores de História.

Segundo Bergson, a fabulação coincide com o resíduo instintivo, com a franja obscura e virtual que circunda a inteligência humana e as representações de caráter intelectual (2005, p. 108). Locus privilegiado de uma virtualidade circundante, faculdade irredutível e persistente que mantém o trânsito aberto entre o plano da inteligência e o domínio do sonho, escava uma zona pré-discursiva, pré-subjetiva ou pré-individual, a qual deve ser levada a sério na produção do conhecimento. A zona pré-discursiva é povoada por figuras indecisas e representações obscuras que ainda não têm o poder de aprisionar as imagens em formas definidas. Nesse contexto, as imagens ainda são exteriores ao núcleo da representação intelectual, isto é, ainda guardam uma relação com o mundo e com a linguagem que não foi penetrada pelos imperativos da lógica e da ação. Não é que não haja lógica na fabulação, mas setrata de uma lógica diferente, impessoal, em que as imagens vagam simplesmente, alastram-se indefinidamente, sem encontrar por limite imediato um sistema de representação modelar e sem deixar, no entanto, de relacionar-se com um potencial de representação. Nesse sentido, ela guarda um conjunto de relações 
particulares com uma dimensão da palavra que não apenas nomeia, "mas inventa e produz encantamento", forma de dizer que levar em consideração a dimensão estritamente utilitária das palavras não implica menosprezar o trabalho que elas realizam concomitantemente no plano do sonho (COUTO, 2011, p. 14).

Partindo dessa consideração, interessa-nos argumentar que, em sua dimensão positiva, a fabulação carrega uma qualidade que não deve ser encarada como um obstáculo ao aprendizado da História científica, mas antes como um meio perceptivo, ou uma função mental, capaz de permitir que essa mesma história seja apreendida em toda sua complexidade. Por complexidade entende-se uma dimensão do aprendizado que leva em conta não somente uma subjetividade modelar, projetada ou imaginada, mas as tensões que por entre as linhas da História constituem uma subjetividade móvel forjada em um jogo de forças entre a potência do estranhamento e a política de identidade (SILVA, 2013). Trata-se, portanto, de uma subjetividade que aprende com a História a agir no mundo, reconhecendo os contornos da historicidade e, ao mesmo tempo, envolto pela nuvem que enseja novos mundos possíveis.

Situada nessa esfera constitutiva, a fabulação aparece como o modo com base no qual o passado pode se oferecer ao presente enquanto expressão da diferença, isto é, como uma dimensão do tempo que não se abre à percepção atual apenas por um exercício de recognição associado à memória empírica, mas que solicita um "olhar de inconformidade" correspondente a um "desassossego do ser" (PEREIRA; TORELLY, 2011). Nesse sentido, a fabulação também pode ser entendida como uma memória do futuro (PIMENTEL, 2010), forma de carregar o passado de uma dimensão intempestiva, "acontecimental" (DOSSE, 2013), desvinculada de uma educação idealizada e articulada a uma noção de educação potencial (LAMELA ADÓ, 2013).

A faculdade fabuladora, situada no contexto constitutivo que referimos aqui, descreve um aspecto da produção de conhecimento que não se dá pela fixação da matéria em determinados estados, mas pela compreensão de que a melhor forma de aprender História não é oferecendo um quadro de imagens fixas do real, mas convidando as novas gerações a intuírem que o tempo é o sinal da mobilidade, ou seja, que o tempo apresenta-se como a própria matéria móvel pela qual as relações entre o que é dizível e o que é visível encontram outras tantas variações, outros tantos pontos futuros, os quais poderão encarnar-se. Em suma, ao contar uma história em sala de aula, a palavra é apreendida nas malhas utilitárias da representação intelectual e, paralelamente à síntese habitual efetuada pela inteligência em função da sua capacidade de ação atual, atinge a dinâmica mental, na qual as imagens se oferecem à fabulação. Trata-se de dois processos distintos e 
complementares. O primeiro nos dá as qualidades de um conhecimento útil à vida cidadã do presente, oferecendo como resultado uma compreensão simétrica e indiferenciada dos lugares ocupados pelas coisas no mundo; o segundo, assemelha-se a um movimento de recriação das formas ou de "literalização" da língua que torna pensável uma cidadania do futuro, a partir de uma faculdade que se desenrola em uma assimetria absoluta, na qual a relação entre o sentido e as coisas é marcada pela mais profunda exterioridade formal. A diferença $e$ a complementaridade entre os dois processos resumem a distância entre o manejo adequado de uma sintaxe ideal e a ousadia de exercitar uma "sintaxe criadora" (MACHADO, 2009, p. 206-207). Forma de dizer que "ao lado de uma língua que nos faça ser mundo, deve coexistir uma outra que nos faça sair do mundo" (COUTO, 2011, p. 24, grifos nossos). Operar, a partir da coexistência entre as formas verbais do ser e do sair, é a pretensão de um conhecimento que insiste em manter uma relação paradoxal e dinâmica entre a inteligência e a fabulação.

Pretender operar a partir desse duplo processo de aprendizagem significa reconhecer que: a) a palavra assume no quadro da vida na cidade uma função de publicidade, servindo como o instrumento por excelência da vida política e dialógica vivida pelos cidadãos (VERNANT, 2004, p. 56); b) não obstante, seria um erro reduzi-la completamente aos limites de uma função instrumental, especialmente quando se trata de ensinar História. A função da palavra não se esgota aí, ou seja, seu caráter de instrumento posto a serviço do conjunto de atribuições de uma vida cidadã não reúne, em si mesmo, a totalidade das suas atribuições. Poder-se-ia dizer mais precisamente que essa função instrumental da palavra expressa somente uma tendência da inteligência, o que não quer dizer que não existam outras tendências, e que estas não solicitem uma faculdade específica, irredutível aos limites da linguagem instrumental, comunicativa e representativa. Não se vive apenas de nomear as coisas, mas de produzir novos lugares para essas coisas (COUTO, 2011).

A desvalorização da palavra certamente está associada ao esquecimento desse segundo processo, como se os ruídos provocados pelo avanço da inteligência tivessem o poder de sufocar o alcance de uma palavra onírica. Ao sublinhar a relação estabelecida entre a palavra e a fabulação, queremos argumentar que a lógica do lucro fácil e imediato, associado atualmente às palavras, não deve desvalorizar o trabalho que essas realizam no sonho.

Ao invés de ser reduzida ou superada de uma vez por todas pelo quadro conceptual do pensamento positivo, a efervescência imaginativa que se desenrola na fabulação mantém-se como uma instância a um só tempo irredutível e suplementar. Trata-se de perceber que não há uma linha irrevogável de evolução em que os movimentos da fabulação seriam ultrapassados pelas categorias do entendimento, 
mas um círculo virtuoso de mútuos empréstimos e associações, no qual a inteligência encontra a raiz de sua gênese em um quadro de significação expandida e a imaginação encontra a possibilidade de encarnar-se em conceitos que se oferecem como um acréscimo à inteligência.

Desse modo, a chave das relações entre a fabulação e a inteligência não se encontra na negação de uma instância pela outra, menos ainda em uma simples relação de contradição entre duas tendências opostas, o que nos daria sempre ao final de um percurso de aprendizagem a figura de uma imaginação infantil e irracional superada pelo poder de abstração dos conceitos. O problema desloca-se desse ponto para tornar-se efetivamente outro quando pensamos essa relação em termos de coexistência e suplementação. A fabulação pode aparecer, então, como a faculdade que expande o horizonte de significação para que o conceito formado seja oferecido não como a descoberta de uma ordem velada pela ignorância, mas como uma novidade que conduz a forma que damos ao conhecimento a "fazer as pazes com o que a precede e a seduz" (LAMELA ADÓ, 2013, p. 34).

É exatamente nisso que a aula expositiva, uma vez já dita como prosaica, encontra-se com a poesia e com o acaso. $\mathrm{O}$ argumento que utilizamos no início deste artigo renova-se agora e reveste-se de outra roupagem, uma vez que, efetivamente, uma aula expositiva que se encontra com a fabulação incorpora a prosa, aproximando-se da poesia e do acaso. E, outro argumento assume a centralidade do que construímos até aqui: ao ministrar uma aula expositiva de História o que fazemos é mesmo redesenhar uma trama, uma cena, fazendo desfilar personagens diante das crianças e dos adolescentes, de maneira que esse desfile seja a constituição de uma trama, um drama, que acende o entorno dos acontecimentos e apazigua o furor pela verdade definitiva do passado. Já o movimento que o professor realiza, no sentido de renovar as possibilidades e impossibilidades acerca do que não é, mas pode ser diferente, é a fabulação, uma vez que esta faculdade está disposta tanto à prosa, como tipicidade da ciência histórica, quanto à poesia, como a arte de produzir ficções, como do acaso, que se constitui como a potência do ouvido e a abertura do professor para os acontecimentos da sala de aula (dos dizeres dos alunos, etc.). Um procedimento da aula de História, no qual o papel do professor é absoluto: um absoluto professor que cumpre o papel de provocar aprendizagens por meio da inserção dos estudantes diretamente no tempo, utilizando-se da criação de ficções que se colocam na origem da construção de qualquer conceito e no reconhecimento de quaisquer quantidades de causas.

Envolvida pelo jogo da fabulação, a aula expositiva já não é mais a expressão simbólica de um professor autoritário, não serve mais a um propósito eminentemente disciplinador. De maneira radicalmente diversa, essa passa a ser o esforço 
cuidadoso e expressivo de um professor que, “com sua voz, gestos e presença, invoca algo do mundo na sala de aula", a qual não transmite apenas uma informação, mas invoca uma atmosfera surpreendente, como se o mundo estivesse ainda aguardando por se fazer mundo, como se a verdade sobre o lugar ocupado pelas coisas e pelos seres não estivesse determinada de uma vez por todas na forma de uma constante sociológica, mas somente aguardando a aula começar. Nesse caso, tratar-se-ia de servir-se da palavra em uma aula expositiva não como algo meramente informativo,

[...] mas também animador, trazido de tal forma que um aluno não pode ajudar, exceto olhar e ouvir. Esses são os momentos bastante raros, mas sempre mágicos, quando os alunos e os professores são arrebatados pela matéria, a qual, simplesmente sendo dita, parece assumir uma voz própria (MASSCHELEIN; SIMONS, 2013, p. 39).

Uma voz que, mesmo que somente por alguns instantes, ameaça a arrancar a percepção do seu estado funcional para conduzi-la até o ponto de encontro com a raridade da experiência poética.

Essas ficções a que chamamos fabulação são pequenas histórias que criamos no contexto de uma aula expositiva, esta na forma ficcional. Como um professor de História que, para poder contar o conceito de Estado Político na concepção de Hobbes, imagina um cruzamento entre duas grandes avenidas, inserindo em cada direção um automóvel, movendo-se um para cada lado, prontos a encontrarem-se no cruzamento. Nesse ponto, o professor pergunta "e se não existisse semáforo, placa de Pare, sinalização na rua ou mesmo guardas de trânsito, o que aconteceria se os automóveis passassem pelo cruzamento no mesmo momento?" E um aluno responde: "os dois acabariam por se matar, professor", e assim a aula continua. Enfim, a ficção que criamos é para projetar problemas e criar provocações na sala de aula que tem aqui, neste texto, um forte fundamento filosófico.

$\mathrm{E}$ isso não quer dizer que possamos denunciar ou abandonar uma exposição que não fabula, que não cria ficções para poder levar os alunos, com o problema e a provocação, na origem dos conceitos, mas queremos mostrar que há um modo de construir uma exposição oral na aula de História que edifica uma outra direção para o encontro do estudante com o conhecimento histórico, uma forma que se vale, como dissemos, de elementos fabulatórios que se constituem de pequenas histórias, às vezes, tendo como personagens os próprios alunos ou, ainda, gestos, músicas, cantos etc.

A arte fabulatória diz respeito a esse encontro da aula de História da escola básica consigo mesma, com um si mesmo da aula que não é a sua própria imagem acabada refletida em uma representação certeira (o que resultaria em um modelo a ser seguido ou em um plano de ação que reduziria por um mecanismo ilusório o 
coeficiente de indeterminação carregado pela aula), mas um si mesmo que envolve um fazer-se, um colocar-se em jogo, um afirmar-se enquanto potência de criação, enquanto força de expressão do que é próprio ao acontecimento educacional. É a respeito da força expressiva desse si mesmo da aula de História na educação básica que pretendemos agora apresentar dois exemplos representativos.

\section{Dyunisius, o fabulador}

Dyunisius encarna um movimento intensivo que implica o envolvimento com a constituição de um tempo aula.

Um tempo aula, eis o que Dyunisius procura constituir. De certo que seu objetivo é jogar cada um dos alunos-espíritos em um mergulho radical e profundo no Oceano aberto do tempo - o seu tempo aula, onde as horas não passam, nada passa e, ao mesmo tempo, revela-se como um fluxo que é pura passagem que absorve a todos em um mesmo e absoluto movimento; não se pergunta pela hora do recreio; não se vive com a esperança da merenda; nem mesmo se solicita para ir ao banheiro.

Parece que aquela aula-buraco, do mergulho profundo, destaca-se de toda a necessidade, mas, sobretudo, suspende toda a ação. De modo que o que se vê não passa de uma nuvem de desterrados, com suas belas inutilidades, que advém de um diletantismo de aprender História.

Desterrados: sem pátria, sem nação, sem identidade, sem cotidiano, muito acima de toda a obrigação habitual; muito distante de toda a produtividade mundana.

Eis uma aula inscrita na exata dimensão do acontecimento. Algo ali acontece. Dyunisius fabulador conta história como quem faz arte e confunde criação e resultado. Faz valer a aprendizagem da História como um exercício livre de criação - que significa descer ao fundo de si mesmo a ponto de impessoalizar-se, como em um retorno à virtualidade do universo, para, sem exigência de vida cotidiana e do presente, ultrapassar o pensado, brincando com o impensado.

$\mathrm{E}$ as crianças aprendem o belo exercício do pensamento. De volta ao caos para criar novidade - "eterna novidade do mundo" -, emergindo em uma embriaguês angustiante e inebriante. Aula-buraco; aula-brincadeira; aula fabulação.

E Dyunisius apresenta-se: "Yo soy Karl Marx y estoy aquí para hacer una revolución" e põe-se a recitar pequenos trechos do Manifesto Comunista e da Contribuição à crítica da economia política, a fim de deixar emergir os conceitos de Valor, Mais Valia e Modo de Produção. E o que poderia ser uma exposição estafante e difícil dos principais conceitos da crítica de Marx ao capitalismo, tornou-se uma exposição que se deu na cesura do tempo e na intercessão entre a arte fabulatória de Dyunisius, a prosa da ciência histórica e o acaso da sala de aula. 


\section{Mas, afinal o que é História?}

Não era muito claro se eles estavam sobrepostos, opostos ou simplesmente separados como três formas distintas. $\mathrm{O}$ fato é que estavam lá, desenhados no quadro como uma espécie de interrogação: um círculo, uma espiral e uma linha. O cansaço de todos os presentes, em virtude de uma aula realizada em horário noturno, contrastava com a curiosidade viva e misteriosa carregada pelo primeiro dia de aula. Junto ao enigmático quadro, dois professores de História circulavam diante de uma turma com cerca de oitenta alunos. Ao invés de enunciar na forma de uma proposição ou de uma afirmação, preferiram provocar - afinal de contas, quem poderia nos dizer o que é História?

A frase provocara uma leve mudança de tensão e uma diversidade de disposições estampava o rosto dos indivíduos. "A história é o que se repete", arriscou uma primeira voz; "a história nos dá lições", sentenciou uma segunda; "a história ensina sobre aquilo que somos", anunciou uma terceira. Agora já não era mais possível voltar atrás. Os alunos haviam entrado no jogo. Um dos professores rabiscou uma nova palavra no quadro, identidade. Esta foi aos poucos cercada por todos os lados, de maneira que em alguns minutos a identidade estava verdadeiramente sitiada. Em torno dessa, gravitavam meio frouxamente termos distintos como cristianismo, racionalismo, subjetividade. Cada um dos termos poderia corresponder, respectivamente, aos diferentes aspectos utilizados pelos alunos para definir o que é História: as lições, a repetição e o sujeito. Ao cabo de alguns minutos, relampejava como um raio no centro do quadro uma nova consideração: "contamos a história de uma identidade em estado de sítio".

Essa identidade sitiada era a forma a partir da qual um regime de exceção era transformado em um modelo normativo. Em todo caso, a aula transcorrera com seus altos, baixos e médios tons. O chamado período pré-histórico fora invocado por alguns minutos, em seguida os antigos, os medievais e os modernos, sempre relacionados a uma tensão entre o que era possível ver, o que era possível dizer em relação a todos esses em virtude das definições que haviam sido dadas pelos alunos. Preocupados ao mesmo tempo em mostrar e em dissolver, os professores pareciam presas ingênuas da sua própria armadilha. Aquela aula parecia girar indefinidamente como uma espiral sem fim. Travava-se uma luta entre a necessidade de dar aos nomes um sentido e a vontade de explodir a legitimidade do sentido nomeado. As coisas não se assentavam. Assim que encontravam um ponto seguro e, em seguida, eram lançadas na indecisão. Era uma aula inconformada. Uma aula desassossegada. As coisas pareciam encontrar ali um espaço de suspensão. A revolução neolítica não conseguia sossegar. Seus elementos giravam, ao invés de 
estacionar. O sedentarismo, a cerâmica, a agricultura e os animais domesticados recusavam-se a aceitar a finalidade de uma destinação definitiva. Aquele jogo fazia as suas voltas.

Esgotara-se o tempo da aula sem que a maioria dos presentes percebesse. Todos encaminhavam-se para o intervalo, alguns conversavam entre si e outros cercavam a dupla de professores de interrogações. Talvez ninguém tenha percebido, mas dentre aquelas formas que haviam sido desenhadas no quadro no início da aula, somente uma restava, era a linha, ostentando a sua arrogância aparentemente indestrutível. Mas, talvez, o que haja de mais aterrador é que ao final do dia as palavras e as formas serão apagadas, e o quadro continuará lá, impassível, em estado de espera, como que a nos fazer uma irônica provocação.

\section{The return of the expositive class in teaching History: grades for the practice of confabulating}

\section{Abstract}

The text is the central element of the professorial act and of teaching history: an expositive class. It argues about the role of the expositive class and questions the narrative character of the History teacher's presentation, since this creates a scenario and gives a dramatic tone to the historical narrative. It questions the didactic exposition and offers an analysis about the criticisms this strategy has received. The Scene, as a means for offering methodological procedures in the strategic teaching of History. In this sense, we seek to deconstruct the dry arid tone which has always accompanied the idea of an expositive class, as well as its close ties with a traditional teaching of History. Similarly, we try to give prominence to different expressive modes accompanying a didactic narrative in History lessons, affirming that this is one of the most important and decisive moments of the teaching-learning relationship in History. Moreover, theorizing about the faculty of Confabulation may well allow a new experience with expositive classes, since it is claimed that an oral presentation in history class implies a confabulating strategy.

Keywords: Expositive class. Confabulation. Education.

\section{Notas}

1 Ver recente publicação sobre o papel dos jogos no ensino de História, que aborda o tema da ludicidade em sala de aula e que propõe fazer da sala de aula um lugar onde passam tempos diversos. GIACOMONI, Marcello Paniz (Org.); PEREIRA, Nilton M. (Org.). Jogos e Ensino de História. Porto Alegre: Ed. Evangraf, 2013. v. 1. 165p.

2 Foucault em, $O$ pensamento do Exterior (1990) propõe que a possibilidade de criação nos leve até um esgotamento da linguagem, na direção de um "ser linguagem", até que a escrita se esgote em si mesma, se volte a si, à sua origem, a uma espécie de "ser que guarda a própria linguagem". Esse esgotar-se implica diminuir até o limite a linguagem como forma de representação de um referente exterior, como significa- 
ção de um sentido pré-definido ou como a comunicação de uma informação dada. Esgotar-se na linguagem ela mesma. A partir de um esgotamento dos aspectos representativo, comunicacional e informativo da linguagem é que pretendemos pensar uma aula expositiva que se dá através da fabulação. Essa estratégia não implica suspender as funções correntes da linguagem, mas dar e ela um novo estatuto, que permite a criação e o pensamento, por fora dos limites da representação.

3 Nesse sentido, ver especialmente a distinção entre imaginação e fabulação. BERGSON, Henri. As duas fontes da moral e da religião. Coimbra: Ed. Almedina, 2005, p. 166-170.

4 Sobre a noção de "literalidade", ver, em especial: SILVA. T. T. Deleuze e a questão de literalidade: uma via alternativa. Educ. Soc., Campinas-SP, v. 26, n. 93, p. 1331-1338, set./dez. 2005; RANCIÈRE, Jacques. $A$ partilha do sensível. São Paulo: Ed. 34, 2009, p. 59-61.

\section{Referências}

LAMELA ADÓ, Máximo Daniel. Educação potencial: autocomédia do intelecto. 2013, 198 p. Tese (Doutorado em Educação) - Universidade Federal do Rio Grande do Sul, Porto Alegre, 2013.

BERGSON, Henri. As duas fontes da moral e da religião. 1. ed. Coimbra: Ed. Almedina, 2005. A evolução criadora. 1. ed. São Paulo: Martins Fontes, 2005.

CAINELLI, Marlene Rosa. A história ensinada no estágio supervisionado do curso de História: a aula expositiva como experiência narrativa. História \& Ensino, Londrina, v. 15, p. 173-182, ago. 2009. Disponível em: < http://www.uel.br/revistas/uel/index.php/histensino/issue/view/756>. Acesso em: 3 fev. 2014.

COUTO, Mia. E se Obama fosse africano?: e outras interinvenções. 1. ed. São Paulo: Companhia das Letras, 2011.

DELEUZE, Gilles. Bergsonismo. Trad. Luiz B. L. Orlandi. São Paulo: Ed. 34, 1999.

DOSSE, François. Renascimento do acontecimento: um desafio para o historiador - entre Esfinge e Fênix. São Paulo: Ed. Unesp, 2013.

FOUCAULT, Michel. O Pensamento do Exterior. São Paulo: Princípio, 1990.

GIACOMONI, Marcello Paniz; PEREIRA, Nilton M. (Orgs.). Jogos e Ensino de História. Porto Alegre: Ed. Evangraf, 2013. v. 1. 165 p.

MACHADO, Roberto. Deleuze, a arte e a filosofia. Rio de Janeiro: Jorge Zahar Ed., 2009.

MASSCHELEIN, Jan; SIMONS, Maarten. Em defesa da escola. Belo Horizonte: Autêntica Editora, 2013.

PEREIRA, Nilton M. Sobre o valor do ensino de história para a vida. Revista Latino-Americana de História, São Leopoldo-RS, v. 2, n. 2, p. 235, ago. 2013.

PEREIRA, Nilton M.; SEFFNER, Fernando. História, leitura e escrita no ensino médio. In: PEREIRA, Nilton Mullet. et al. (Orgs.). Ler e Escrever: compromisso no Ensino Médio. Porto Alegre: Ed. da UFRGS, 2008, v. 1. p. 165-180.

PEREIRA, Nilton; TORELLY, Gabriel. Olhar da inconformidade: ensino de história e acontecimento. História e-história, 2011. 
PIMENTEL, Mariana Rodrigues. Fabulação: a memória do futuro. 2010. Tese (Doutorado em Letras) - Pontifícia Universidade Católica, Rio de Janeiro, 2010.

RANCIÈRE, Jacques. A partilha do sensível. São Paulo: Ed. 34, 2009.

SEFFNER, Fernando. Saberes da docência, saberes da disciplina e muitos imprevistos: atravessamentos no território do ensino de História. In: BARROSO, Véra Lucia Maciel, et al. (Orgs.). Ensino de História: desafios contemporâneos. Porto Alegre: Est: Exclamação: Anpuh/rs, 2010.

SILVA, Tomaz Tadeu da. Deleuze e a questão da literalidade: uma via alternativa. Educ. Soc., Campinas-SP, v. 26, n. 93, p. 1331-1338, set./dez. 2005.

Identidade e diferença: a perspectiva dos estudos culturais. Petrópolis: Vozes, 2013.

VERNANT, Jean-Pierre. As origens do pensamento grego. Rio de Janeiro: Difel, 2004. 